\title{
Efficacy and safety of tocilizumab in Korean patients with active rheumatoid arthritis
}

\author{
Han Joo Baek ${ }^{1}$, Mie Jin Lim², Won Park ${ }^{2}$, Sung Hwan Park ${ }^{3}$, Seung-Cheol Shim, Dae-Hyun Yoo \\ Hyun Ah Kim ${ }^{6}$, Soo Kon Lee ${ }^{7}$, Yun Jong Lee ${ }^{8}$, Young Eun Park ${ }^{9}$, Hoon-Suk Cha ${ }^{10}$, and Yeong-Wook Song ${ }^{11,12,13}$
}

Division of Rheumatology, Department of Internal Medicine, ${ }^{1}$ Gachon University Gil Medical Center, Incheon; ${ }^{2}$ Inha University Hospital, Incheon; ${ }^{3}$ College of Medicine, Seoul St. Mary's Hospital, The Catholic University of Korea, Seoul; ${ }^{4}$ Chungnam National University Hospital, Daejeon; ${ }^{5}$ Hanyang University Seoul Hospital, Seoul; ${ }^{6}$ Hallym University Sacred Heart Hospital, Anyang; ${ }^{7}$ Severance Hospital, Yonsei University College of Medicine, Seoul; ${ }^{8}$ Seoul National University Bundang Hospital, Seongnam; ${ }^{9}$ Pusan National University Hospital, Busan; ${ }^{10}$ Samsung Medical Center, Sungkyunkwan University School of Medicine, Seoul; ${ }^{11}$ Seoul National University Hospital, Seoul; ${ }^{12}$ Department of Molecular Medicine and Biopharmaceutical Sciences, Graduate School of Convergence Science and Technology, Seoul National University, Seoul; ${ }^{13}$ Medical Research Center, Seoul National University College of Medicine, Seoul, Korea

Background/Aims: To investigate the efficacy and safety of tocilizumab (TCZ) humanized anti-interleukin- 6 receptor monoclonal antibody, in Korean patients with active rheumatoid arthritis (RA) refractory to conventional disease modifying anti-rheumatic drugs (DMARDs) including methotrexate (MTX)

Methods: The main study was a 24-week, randomized, double-blind, controlled trial that was followed by a 48 -week, open-labeled, extension phase. TCZ $(8 \mathrm{mg} / \mathrm{kg})$ or placebo was intravenously administered every 4 weeks.

Results: Those treated with TCZ showed more favorable outcomes in terms of $20 \%$ according to the American College of Rheumatology response criteria (ACR2O) and ACR50 responses, individual parameters of ACR core set, disease activity score in 28 joints (DAS28) remission, and European League Against Rheumatism (EULAR) response at week 24. These improvements were maintained or increased during the extension period. DAS28 remission at week 72 was associated with EULAR good response at week 12. The patients who experienced any adverse event (AE) were more frequent in the TCZ group compared to the placebo group. Most AEs were mild or moderate in intensity, although TCZ therapy had possible AEs including serious infection, abnormal liver function, and atherogenic lipid profile.

Conclusions: TCZ infusion add-on is highly efficacious and well-tolerated in Korean patients with active RA refractory to conventional DMARDs including MTX. EULAR good response at week 12 could predict DAS28 remission at week 72 .

Keywords: Arthritis, rheumatoid; Tocilizumab; Korean

\section{INTRODUCTION}

Revised : June 6, 2017

Accepted: July 11, 2017

\section{Correspondence to}

Yeong-Wook Song, M.D.

Division of Rheumatology, Department of Internal Medicine, Seoul National University Hospital, 101 Daehak-ro, Jongno-gu, Seoul 03080, Korea

Tel: +82-2-2072-2234

Fax: +82-2-762-9662

E-mail: ysong@snu.ac.kr
Rheumatoid arthritis (RA) is a systemic inflammatory disease characterized by fatigue, joint pain, and swelling, which results in loss of function, progressive disability, and increased morbidity and mortality [1,2]. Targeting the proinflammatory cytokine tumor necrosis factor (TNF) using monoclo- nal antibody is an effective therapeutic option for RA patients, especially those with an inadequate response to conventional disease modifying anti-rheumatic drugs (DMARDs) including methotrexate (MTX) [2]. However, up to $40 \%$ of patients have an inadequate response to anti-TNF treatment and there has been an unmet need for new drugs with new modes of action 
for RA [3].

Interleukin-6 (IL-6) is a proinflammatory cytokine involved in multiple immunologic processes, such as T cell activation, B cell proliferation, and initiation of acutephase protein [4]. The serum level of IL-6 has been correlated with disease activity of RA. Thus, IL-6 is thought to play a major pathological role in RA [5]. Tocilizumab (TCZ) is a humanized anti-IL-6 receptor monoclonal antibody that can block IL-6 receptor signaling and the subsequent pro-inflammatory process [6].

Several clinical trials have demonstrated the efficacy and safety of TCZ monotherapy or in combination with conventional DMARDs in patients with moderate to severe RA [7-11]. Recently, the European League Against Rheumatism (EULAR) recommended TCZ as a biologic DMARD for patients with RA refractory to conventional DMARDs [12].

Most clinical trials for TCZ have been conducted in Caucasian or Japanese people. We investigated the efficacy and safety of TCZ in Korean patients with active RA refractory to conventional DMARDs including MTX. We also conducted a post hoc study to look for clinical parameters associated with disease activity score in 28 joints (DAS28) remission induced by TCZ treatment.

\section{METHODS}

\section{Patients}

Patients were eligible for the study if they had been diagnosed with RA according to the 1987 American College of Rheumatology (ACR) criteria [13] and had active disease refractory to MTX with or without other conventional DMARDs. Active RA was defined by a swollen joint count $(\mathrm{SJC}) \geq 6$ from the total of 66 , tender joint count (TJC) $\geq 8$ from the total of 68 , and serum C-reactive protein level $\geq 1 \mathrm{mg} / \mathrm{dL}$ or erythrocyte sedimentation rate $(\mathrm{ESR}) \geq 28$ $\mathrm{mm} / \mathrm{hr}$. Stable dose of DMARDs was required for at least 8 weeks prior to study entry. Oral glucocorticoids (up to prednisone $10 \mathrm{mg} /$ day equivalents) and non-steroidal anti-inflammatory drugs (NSAIDs) were permitted if the dose was stable for at least 6 weeks. Patients were excluded if they had concurrent active illnesses, such as infection and malignancy, previous history of hypersensitivity, or contraindication to treatment with human, humanized, or mouse monoclonal antibody. All subjects were screened for latent tuberculosis according to the Korean guideline for patients starting therapy with biologic agents. Those with latent tuberculosis were excluded if they refused the medication [14].

\section{Study design}

The study was composed of main and extension trials. The main study was a 24-week, phase III, randomized, double-blind, placebo-controlled, multicenter trial. It was conducted from October 2009 to October 2010. A total of 140 patients were screened and 99 patients were randomly assigned to either the TCZ group or placebo group. Randomization was stratified according to whether patients used MTX alone or in combination with other DMARDs. TCZ at a dose of $8 \mathrm{mg} / \mathrm{kg}$ or placebo was administered intravenously in a blinded manner with an approximately 6o-minute infusion every 4 weeks. Background treatment with DMARDs was maintained during the study. If a patient showed no improvement by week 12 or less than $20 \%$ improvement by week 16, based on SJC and TJC, one rescue therapy was permitted. Rescue therapy included change of DMARDs, increase in dose of DMARDs, intra-articular glucocorticoid injection to one inflamed joint, or increase in dose of oral glucocorticoid (up to prednisone $10 \mathrm{mg} /$ day equivalents). Those who received the rescue therapy were regarded as non-responders for ACR response.

Patients who completed the main study or withdrew from the main study due to lack of efficacy of study drug could be enrolled in a subsequent 48-week, open-labeled extension trial conducted to September 2011. All patients who participated in the extension study were given TCZ at the same dose and interval with the main study. Modification of NSAID, DMARD, or glucocorticoid therapy was allowed during the extension period according to the investigator's decision. The dose of oral glucocorticoid could be increased (up to prednisone $10 \mathrm{mg}$ /day equivalents) or decreased until week 40 . Intra-articular glucocorticoid injection was also permitted until week 40.

\section{Efficacy assessment}

The primary endpoint of the main trial was the proportion of patients who achieved improvement of $20 \%$ according to the ACR response criteria (ACR2O) [15] at week 24. Secondary end points included the proportion of pa- 
tients with 50\% and 70\% improvement by ACR criteria (ACR50 and ACR7o, respectively); remission based on DAS28 using ESR [16]; EULAR response [17]; the proportion of patients who withdrew from the trial due to lack of efficacy and received the rescue medication; change in each ACR core set parameter, DAS28 score, hemoglobin level, rheumatoid factor (RF) titer, and Health Assessment Questionnaire disability index (HAQ-DI) at week 24 [18]; and the time interval to reach ACR2O, ACR50, and ACR7o responses. Efficacy variables were assessed as secondary endpoints in the extension study.

\section{Safety assessment}

Safety was assessed as secondary and primary endpoints of the main and the extension study, respectively. Adverse events (AEs), serious AEs, adverse drug reactions (ADRs), and clinically significant changes in laboratory test results during the study period were collected. All $\mathrm{AE}$ and ADR data were summarized according to World Health Organization Adverse Reaction Terminology system organ class and preferred terms [19].

\section{Statistical analyses}

The sample size for the main study was calculated with a significance level of 0.05 (two-sided test) and statistical power of $80 \%$ to verify a hypothetical difference of $30 \%$ at ACR2o response between the TCZ and the placebo groups with an intention-to-treat analysis. The clinical trial was designed with 45 subjects in each group considering the uncertainties of calculation and subject dropout during the study.

The analysis of efficacy was performed on an intention-to-treat basis in the main study. Primary and secondary outcome variables were compared between the TCZ and the placebo groups by chi-square test, Fisher exact test, two-sample $t$ test, or Wilcoxon's rank sum test. The last observation carried forward rule was applied for the missing SJC or TJC data. Safety analysis was conducted based on the number of AEs that occurred during the study. Chi-square test or Fisher exact test was used to compare the incidence of AEs. Paired $t$ test was used to analyze the changes of the continuous variables. To search for parameters associated with DAS28 remission at week 72, univariate analysis was performed when comparing the patients with remission and those without remission. All statistical comparisons were done by two-tailed analyses and the difference was considered as significant if $p$ value was $<0.05$.

\section{Ethics statement}

The study was approved by relevant Institutional Review Boards (0904-037-278) and written informed consent was obtained from each patient. The study was conducted in accordance with the International Conference on Harmonization Guidelines for Good Clinical Practice (GCP) and the Declaration of Helsinki. These trials are registered at www.clinicaltrial.gov as NCTo1211834 and NCTo1256736.

\section{RESULTS}

\section{Characteristics of the patients}

A total of 99 patients were enrolled in the main 24-week clinical trial from 11 institutions. They were randomized to the TCZ ( $n=48)$ or the placebo group $(n=51)$. Eighty patients $(80.8 \%)$ completed this study. Subsequent to the main study, these 80 completers and nine patients who withdrew from the main study due to inefficacy of the placebo $(n=5)$ and GCP or protocol violations ( $n=4$; three from the placebo group and one from the TCZ group) participated in the open-labeled extension study. Seventy-two (80\%) completed the extension study (Fig. 1). Baseline characteristics of the TCZ and placebo groups from the main study were comparable, except for the proportion of patients with RF (Table 1).

\section{Efficacy assessment}

\section{Main study}

Patients treated with TCZ showed significant improvements by clinical and laboratory parameters compared with those treated with placebo (Table 2). The proportion of ACR2o responders was significantly higher in the TCZ group than in the placebo group (61.7\% vs. $16.7 \%$, $p<0.0001)$ at week 24. The proportion of patients with ACR5o response, DAS28 remission, and EULAR good response were also significantly increased in TCZ-treated patients. The TCZ-treated patients revealed favorable outcomes in change of DAS2 8 from the baseline and individual parameters of ACR core set, except for HAQDI. Efficacy of TCZ was apparent as early as 4 to 8 weeks 


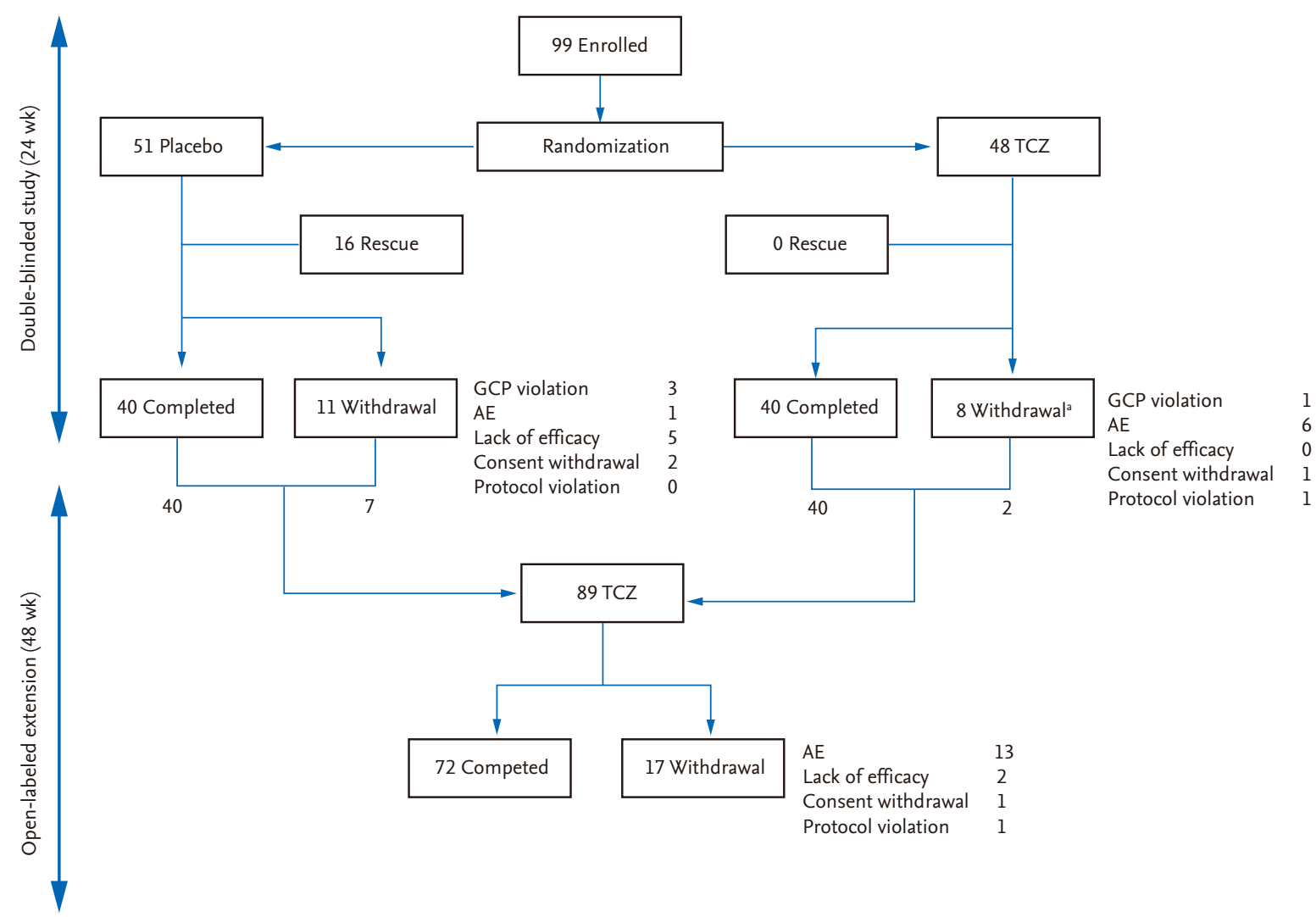

Figure 1. Patient disposition. TCZ, tocilizumab; GCP, Good Clinical Practice; AE, adverse effect. ${ }^{\mathrm{a} O n e}$ patient was related with both AE and GCP violation.

after infusion. The level of hemoglobin was significantly elevated at week 24 in the TCZ group compared with the placebo group. The titer of RF significantly decreased in seropositive patients with TCZ treatment at week 24, whereas it increased in those with placebo (Table 2).

\section{Extension study}

Forty-two patients from the TCZ group and 47 patients from the placebo group participated in the extension study. The efficacy endpoints were assessed for the patients who were treated with TCZ successively during the main and extension study periods. At week 72, ACR20, ACR50, and ACR70 response was observed in 87.9\%, $63.6 \%$, and $36.4 \%$ of the patients, respectively. Eightyeight percent and $66.7 \%$ of the patients achieved EULAR good response and DAS28 remission at week 72, respectively (Table 3). Those who began to be infused with TCZ from the extension study caught up to the response of the patients who received TCZ from the main study (Fig. 2). The level of hemoglobin at week 72 significantly increased from baseline $(p<0.0001)$. The titer of RF at week 72 was not statistically different from the baseline value (Table 3). The efficacy of TCZ was not significantly different according to the background DMARD therapy (data not shown).

\section{Safety assessment}

Main study

Ninety-nine patients who received TCZ $(n=48)$ or placebo $(n=51)$ at least once during the study were assessed for safety. The patients who experienced any AEs were more frequent in the TCZ group compared to the placebo group (89.6\% vs. $60.8 \%, p=0.001$ ). The occurrence of AEs associated with infection was $41.7 \%$ of the patients in the TCZ group, which was higher than those in the placebo group (23.5\%, $p=0.0538$ ) (Table 4$)$.

TCZ treatment showed some changes in laboratory measurements at week 24 . The patients in the TCZ group presented a decline in counts of leukocytes, neu- 
Table 1. Baseline demographic and clinical characteristics of the patients from the main study (intent-to-treat population)

\begin{tabular}{|c|c|c|}
\hline Characteristic & Placebo $(n=48)$ & Tocilizumab $(\mathrm{n}=47)$ \\
\hline Age, yr & $52.0 \pm 12.2$ & $52.6 \pm 10.4$ \\
\hline Weight, kg & $57 \cdot 7 \pm 10.2$ & $55.2 \pm 8.0$ \\
\hline Female sex & $42(87 \cdot 5)$ & $42(89.4)$ \\
\hline Smoking & $3(6.3)$ & $2(4 \cdot 3)$ \\
\hline Disease duration, yr & $8.9 \pm 7.17$ & $10.8 \pm 7.8$ \\
\hline \multicolumn{3}{|l|}{ ACR functional class } \\
\hline $\mathrm{I}$ & $6(12.5)$ & $10(21.3)$ \\
\hline II & $33(68.8)$ & $22(46.8)$ \\
\hline III & $9(18.8)$ & $15(31.9)$ \\
\hline IV & 0 & 0 \\
\hline DAS28-ESR & $6.1 \pm 1.1$ & $6.1 \pm 0.8$ \\
\hline \multicolumn{3}{|l|}{ ACR core set measures } \\
\hline TJC (66 assessed) & $22.8 \pm 14.0$ & $21.8 \pm 12.1$ \\
\hline SJC (68 assessed) & $11.9 \pm 10.0$ & $10.3 \pm 4.9$ \\
\hline Patient's pain VAS, mmª & $60.7 \pm 21.8$ & $58.6 \pm 23.1$ \\
\hline Patient's global VAS, mm ${ }^{\mathrm{b}}$ & $65.9 \pm 20.0$ & $64.0 \pm 24.4$ \\
\hline Physician's global VAS, mm $^{\mathrm{c}}$ & $63.0 \pm 18.1$ & $63.4 \pm 15 \cdot 7$ \\
\hline $\mathrm{ESR}, \mathrm{mm} / \mathrm{hr}$ & $52.5 \pm 27.1$ & $52.2 \pm 25.6$ \\
\hline $\mathrm{CRP}, \mathrm{mg} / \mathrm{dL}$ & $3.0 \pm 2.7$ & $2.7 \pm 2.5$ \\
\hline HAQ-DI & $1.4 \pm 0.6$ & $1.3 \pm 0.7$ \\
\hline \multicolumn{3}{|l|}{ DMARDs } \\
\hline MTX alone & $26(54.2)$ & $28(59.6)$ \\
\hline MTX plus hydroxychloroquine & $19(39.6)$ & $13(27 \cdot 7)$ \\
\hline MTX plus sulfasalazine & $3(6.3)$ & $6(12.8)$ \\
\hline Dosage of MTX, mg/wk & $13.6 \pm 3 \cdot 4$ & $14 \cdot 5 \pm 3 \cdot 0$ \\
\hline Oral glucocorticoid $^{\mathrm{d}}$ & $45(93.8)$ & $39(83.0)$ \\
\hline RF positivity & $24(50.0)$ & $34(72.3)^{\mathrm{e}}$ \\
\hline RF titer ${ }^{\mathrm{f}}, \mathrm{U} / \mathrm{mL}$ & $164 \pm 217$ & $162 \pm 191$ \\
\hline Hemoglobin, g/dL & $12.0 \pm 1.4$ & $11.7 \pm 1.3$ \\
\hline
\end{tabular}

Values are presented as mean $\pm \mathrm{SD}$ or number $(\%)$.

ACR, American College of Rheumatology; DAS28, disease activity score in 28 joints; ESR, erythrocyte sedimentation rate; TJC, tender joint count; SJC, swollen joint count; VAS, visual analog scale; CRP, C-reactive protein; HAQ-DI, Health Assessment Questionnaire disability index; DMARD, disease modifying anti-rheumatic drug; MTX, methotrexate; RF, rheumatoid factor.

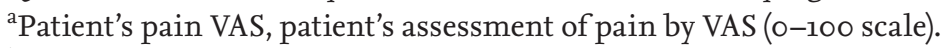

'Patient's global VAS, patient's global assessment of disease activity by VAS (o-10o scale).

'Physician's global VAS, physician's global assessment of disease activity by VAS (o-10o scale).

${ }^{\mathrm{d}}$ Oralglucocortocoid was permitted up to prednisone $10 \mathrm{mg} /$ day equivalents at the baseline if the dose was stable for at least 6 weeks.

'Tocilizumab and placebo group compared $(p=0.0256)$ by chi-square test.

${ }^{f}$ Mean $R F$ titer was calculated from the patients with positive $R F(R F \geq 15 \mathrm{U} / \mathrm{mL})$. 
Table 2. Clinical efficacy of the tocilizumab vs. the placebo group at week 24 from the main study (intent-to-treat population)

\begin{tabular}{|c|c|c|c|}
\hline Variable & Placebo $(n=48)$ & Tocilizumab $(\mathrm{n}=47)$ & $p$ value \\
\hline \multicolumn{4}{|l|}{ ACR response } \\
\hline ACR2o improvement & $8(16.7)$ & $29(61.7)$ & $<0.0001$ \\
\hline ACR5o improvement & $1(2.1)$ & $14(29.8)$ & 0.0002 \\
\hline ACR7o improvement & $1(2.1)$ & $2(4 \cdot 3)$ & NS \\
\hline Change in DAS28-ESR & $-1.2 \pm 1.0$ & $-3.2 \pm 1.0$ & $<0.0001$ \\
\hline DAS28-ESR remission & $1(3 \cdot 3)$ & $17(42.5)$ & 0.0002 \\
\hline EULAR response & & & $<0.0001$ \\
\hline Good & $1(2.1)$ & $25(53.2)$ & \\
\hline Moderate & $16(33 \cdot 3)$ & $15(31.9)$ & \\
\hline No & $31(64.6)$ & $7(14.9)$ & \\
\hline \multicolumn{4}{|l|}{ Change in ACR core set } \\
\hline TJC (66 assessed) & $-4.7 \pm 12.4$ & $-10.1 \pm 11.6$ & 0.0305 \\
\hline SJC (68 assessed $)$ & $-3.2 \pm 8.4$ & $-6.8 \pm 4.6$ & 0.0111 \\
\hline Patient's pain VAS, mm ${ }^{\mathrm{a}}$ & $-13.9 \pm 32.3$ & $-28.4 \pm 26.0$ & 0.0415 \\
\hline Patient's global VAS, mm & $-15.6 \pm 30.8$ & $-28.6 \pm 27.9$ & 0.0237 \\
\hline Physician's global VAS, mm ${ }^{\mathrm{c}}$ & $-21.5 \pm 22.6$ & $-39.5 \pm 16.2$ & 0.0002 \\
\hline $\mathrm{ESR}, \mathrm{mm} / \mathrm{hr}$ & $-11.1 \pm 28.2$ & $-47.0 \pm 21.8$ & $<0.0001$ \\
\hline $\mathrm{CRP}, \mathrm{mg} / \mathrm{dL}$ & $-1.0 \pm 2.5$ & $-2.1 \pm 2.1$ & 0.0332 \\
\hline HAQ-DI & $-0.2 \pm 0.5$ & $-0.3 \pm 0.5$ & NS \\
\hline Change in $\mathrm{Hb}$ level, g/dL & $-0.1 \pm 1.2$ & $0.9 \pm 1.0$ & 0.0002 \\
\hline Change in RF titer ${ }^{\mathrm{d}}, \mathrm{U} / \mathrm{mL}$ & $29.4 \pm 100.8$ & $-53.8 \pm 81.9$ & 0.0055 \\
\hline
\end{tabular}

Values are presented as number (\%) or mean $\pm \mathrm{SD}$.

ACR, American College of Rheumatology; NS, not significant; DAS28, disease activity score in 28 joints; ESR, erythrocyte sedimentation rate; EULAR, European League Against Rheumatism; TJC, tender joint count; SJC, swollen joint count; VAS, visual analog scale; CRP, C-reactive protein; HAQ-DI, Health Assessment Questionnaire disability index; Hb, hemoglobin; RF, rheumatoid factor.

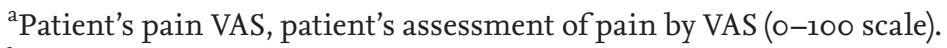

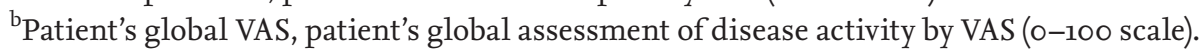

'Physician's global VAS, physician's global assessment of disease activity by VAS (o-10o scale).

${ }^{\mathrm{d}}$ Changes in RF titer were calculated from patients with positive $\mathrm{RF}$ at baseline $(\mathrm{RF} \geq 15 \mathrm{U} / \mathrm{mL})$.

trophils, and platelets at week 24 from baseline. However, the number of patients who decreased in cell counts from normal baseline to low values at week 24 differed significantly from the placebo group only in terms of leukocytes (17.5\% vs. $0 \%, p=0.016)$. The mean levels of aspartate transaminase (AST) and alanine transaminase (ALT) increased at week 24 in the TCZ group, but were within the normal range. An increase in the AST and ALT levels from the normal baseline to $>40 \mathrm{IU} / \mathrm{L}$ in the TCZ group was comparable to the placebo group. The concentrations of serum total cholesterol, low density li- poprotein (LDL), and high density lipoprotein (HDL) of the TCZ-treated patients were elevated at week 24 compared with those of placebos, although that of triglyceride (TG) was not. The numbers of patients who had an increase in the levels of lipid from normal baseline values were not statistically different between the TCZ and the placebo groups (Fig. 3).

\section{Extension study}

Safety was assessed for 89 patients who were infused with TCZ once or more during the main or extension study 
Table 3. Clinical efficacy from those who were treated with tocilizumab successively during the main and extension study periods

\begin{tabular}{|c|c|c|c|}
\hline Variable & Baseline $(n=42)$ & Week $24(n=42)$ & Week $72(\mathrm{n}=33)$ \\
\hline \multicolumn{4}{|l|}{ ACR response } \\
\hline ACR2o improvement & & $30(71.4)$ & $29(87.9)$ \\
\hline ACR50 improvement & & $15(35.7)$ & $21(63.6)$ \\
\hline ACR70 improvement & & $3(7.14)$ & $12(36.4)$ \\
\hline DAS28-ESR & $6.06 \pm 0.69$ & $2.82 \pm 1.00^{\mathrm{a}}$ & $2.28 \pm 0.98^{\mathrm{a}}$ \\
\hline DAS28-ESR remission & & $18(43.9)$ & $22(66.7)$ \\
\hline \multicolumn{4}{|l|}{ EULAR response } \\
\hline Good & & $26(63.4)$ & $29(87.9)$ \\
\hline Moderate & & $15(36.6)$ & $4(12.1)$ \\
\hline No & & o & o \\
\hline \multicolumn{4}{|l|}{ ACR core set measures } \\
\hline TJC (66 assessed) & $20.7 \pm 11.2$ & $10.6 \pm 10.4^{\mathrm{a}}$ & $5.26 \pm 6.64^{\mathrm{a}}$ \\
\hline SJC (68 assessed) & $9.88 \pm 4.82$ & $3.40 \pm 3.63^{\mathrm{a}}$ & $1.86 \pm 2.36^{\mathrm{a}}$ \\
\hline Patient's pain VAS, mm & $56.4 \pm 22.1$ & $27.2 \pm 20.2^{\mathrm{a}}$ & $22.9 \pm 15.4^{\mathrm{a}}$ \\
\hline Patient's global VAS, $\mathrm{mm}^{\mathrm{c}}$ & $62.3 \pm 23.9$ & $32.4 \pm 21.9^{\mathrm{a}}$ & $26.3 \pm 20.3^{\mathrm{a}}$ \\
\hline Physician's global VAS, mm ${ }^{\mathrm{d}}$ & $61.7 \pm 15.4$ & $21.5 \pm 15 \cdot 7^{\mathrm{a}}$ & $15 \cdot 9 \pm 13 \cdot 6^{\mathrm{a}}$ \\
\hline $\mathrm{ESR}, \mathrm{mm} / \mathrm{hr}$ & $50.7 \pm 23.8$ & $5.15 \pm 6.28^{\mathrm{a}}$ & $5 \cdot 97 \pm 7.20^{\mathrm{a}}$ \\
\hline $\mathrm{CRP}, \mathrm{mg} / \mathrm{dL}$ & $2.21 \pm 2.05$ & $0.11 \pm 0.27^{\mathrm{a}}$ & $0.10 \pm 0.26^{\mathrm{a}}$ \\
\hline HAQ-DI & $1.18 \pm 0.66$ & $0.83 \pm 0.61^{a}$ & $0.72 \pm 0.61^{a}$ \\
\hline Hb level, g/dL & $11.8 \pm 1.24$ & $12.7 \pm 1.36^{\mathrm{a}}$ & $13.3 \pm 1.40^{\mathrm{a}}$ \\
\hline RF titer ${ }^{\mathrm{e}}, \mathrm{U} / \mathrm{mL}$ & $159 \pm 189$ & - & $125 \pm 143$ \\
\hline
\end{tabular}

Values are presented as number (\%) or mean \pm SD.

ACR, American College of Rheumatology; DAS28, disease activity score in 28 joints; ESR, erythrocyte sedimentation rate; EULAR, European League Against Rheumatism; TJC, tender joint count; SJC, swollen joint count; VAS, visual analog scale; CRP, C-reactive protein; HAQ-DI, Health Assessment Questionnaire disability index; Hb, hemoglobin; RF, rheumatoid factor.

${ }^{a} p<0.0001$ compared to baseline.

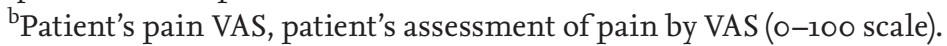

${ }^{\text {c} P a t i e n t ' s ~ g l o b a l ~ V A S, ~ p a t i e n t ' s ~ g l o b a l ~ a s s e s s m e n t ~ o f ~ d i s e a s e ~ a c t i v i t y ~ b y ~ V A S ~(o-10 o ~ s c a l e) . ~}$

dPhysician's global VAS, physician's global assessment of disease activity by VAS (o-100 scale).

${ }^{\mathrm{e}}$ Means of RF titer were calculated from the patients with positive $\mathrm{RF}$ at the baseline $(\mathrm{RF} \geq 15 \mathrm{U} / \mathrm{mL})$.

period (Table 5). A total of 1,181 TCZ infusions were administered for $1.04 \pm 0.31$ years on average. Eighty-four patients (94.4\%) experienced one or more AEs and the incidence of AEs was 5.28 per patient. Any ADRs occurred in 66 patients $(74.2 \%)$ with the incidence of 3.35 per patient. Rate of AEs per 100 patients-years was 505.7 events and was highest during the first 3 months. Twenty-one AEs from 13 patients (14.6\%) led to discontinuation of the study. The intensity of most AEs was mild (85.3\%) or moderate (11.1\%). Twenty-three patients $(25.8 \%)$ had 29 serious AEs, of which 19 events from 14 patients (15.7\%) were drug-related. These serious ADRs included nine infection-related events and others including gastric ulcer, increased AST, increased ALT, fracture, avascular bone necrosis, uterine cervical dysplasia, lung adenocarcinoma, thrombophlebitis, pulmonary embolism, and abortion. A 68-year-old woman with a ureteral stone died from sepsis due to urinary tract infection following 12 infusions of TCZ. Most frequent ADRs were pharyngitis $(\mathrm{n}=21)$, increased ALT $(\mathrm{n}=19)$, increased AST ( $\mathrm{n}=$ 16), leukopenia $(n=17)$, granulocytopenia $(n=16)$, and hypercholesterolemia $(\mathrm{n}=12)$.

Forty-seven patients (52.8\%) experienced 72 infection-related AEs (Table 5). Fifty-five events from 37 patients (41.6\%) were drug-related. These included upper respiratory tract infection $(\mathrm{n}=27)$ including pharyngitis, 


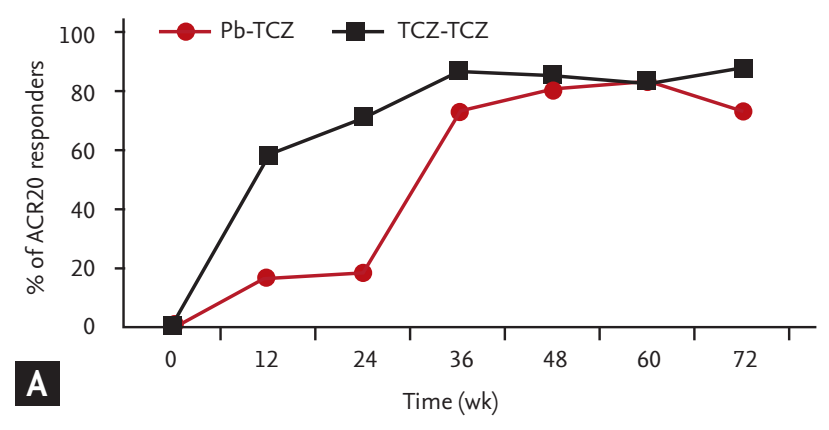

Table 4. Adverse events from the main study (safety population)

\begin{tabular}{|c|c|c|}
\hline Variable & $\begin{array}{c}\text { Placebo } \\
(\mathrm{n}=51)\end{array}$ & $\begin{array}{l}\text { Tocilizumab } \\
\quad(\mathrm{n}=48)\end{array}$ \\
\hline Total no. of AEs & 66 & 166 \\
\hline Patients with any AE & $31(60.8)$ & $43(89.6)^{b}$ \\
\hline Total no. of ADRs & 27 & 112 \\
\hline Patients with any ADR & $15(29.4)$ & $33(68.8)^{c}$ \\
\hline \multicolumn{3}{|l|}{ Intensity of $\mathrm{AEs}^{\mathrm{a}}$} \\
\hline Mild & $60(90.9)$ & $135(81.3)$ \\
\hline Moderate & $6(9.1)$ & $22(13 \cdot 3)$ \\
\hline Severe & o & $9(5 \cdot 4)$ \\
\hline Serious AEs & 62 & 153 \\
\hline AEs leading to discontinuation & 1 & 8 \\
\hline AEs leading to dose interruption & 3 & 12 \\
\hline Death & 0 & 0 \\
\hline \multicolumn{3}{|l|}{ Common AEs by SOC } \\
\hline $\begin{array}{l}\text { Body as whole general } \\
\text { disorders }\end{array}$ & 2 & 11 \\
\hline Gastrointestinal disorders & 5 & 24 \\
\hline Liver and biliary disorders & 5 & 25 \\
\hline $\begin{array}{l}\text { Metabolic and nutritional } \\
\text { disorders }\end{array}$ & 8 & 19 \\
\hline Musculoskeletal disorders & 13 & 12 \\
\hline Respiratory disorders & 14 & 26 \\
\hline $\begin{array}{l}\text { Skin and appendages } \\
\text { disorders }\end{array}$ & 8 & 10 \\
\hline White cell and RES disorders & 16 & 16 \\
\hline Infection-related AEs & 15 & 23 \\
\hline Patients with infectious AEs & $12(23 \cdot 5)$ & $20(41.7)^{\mathrm{d}}$ \\
\hline $\begin{array}{l}\text { Infectious AEs/100 patient } \\
\text { years, \% }\end{array}$ & 65.0 & 108.7 \\
\hline Serious infectious AEs & 1 & 5 \\
\hline $\begin{array}{l}\text { Patients with serious } \\
\text { infectious AEs }\end{array}$ & $1(2.0)$ & $4(8.3)$ \\
\hline $\begin{array}{l}\text { Serious infection/10o patient } \\
\text { years, \% }\end{array}$ & $4 \cdot 3$ & 22.6 \\
\hline Infectious ADRs & 11 & 17 \\
\hline Patients with infectious ADRs & $8(15.7)$ & $16(33.3)^{\mathrm{e}}$ \\
\hline
\end{tabular}

lung infection $(n=4)$ including bronchitis, pneumonia, and empyema, fungal dermatitis $(\mathrm{n}=5)$, herpes zoster $(\mathrm{n}=4)$, cellulitis $(\mathrm{n}=3)$, cystitis $(\mathrm{n}=3)$, herpes simplex $(\mathrm{n}=2)$, and urinary tract infection $(\mathrm{n}=2)$. Ten infusion reactions occurred in six patients (6.7\%). These reactions developed within 24 hours following the end of drug administration. No one withdrew from the study due to these AEs.

Neutropenia, elevated AST or ALT level, and abnormal lipid profile were remarkable changes in laboratory measurements relevant to AE during the whole study

Values are presented as number or number (\%).

AE, adverse event; ADR, adverse drug reaction; SOC, system organ class; RES, reticulo-endothelial system.

${ }^{\mathrm{a}}$ Number of events (column \% for each category).

${ }^{b} p=0.0010,{ }^{c} p<0.0001,{ }^{d} p=0.0538$, and ${ }^{e} p=0.0406$ when comparing with the placebo group. 

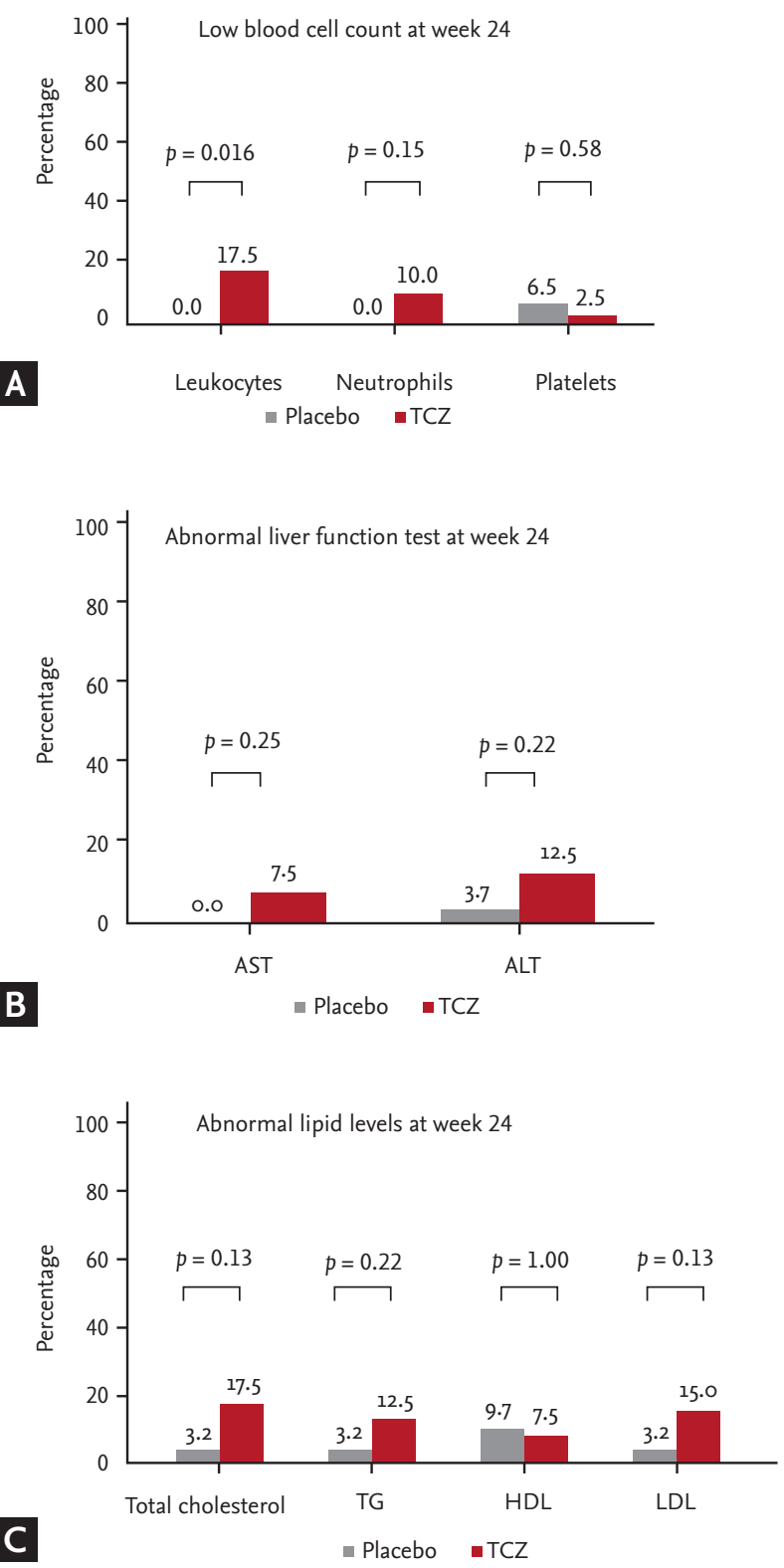

Figure 3. Laboratory measurements relevant to AE at week 24. (A) Percentage of patients who showed a decrease from normal baseline to low cell counts at week 24. (B) Percentage of patients who showed an increase from normal baseline to abnormal aspartate transaminase (AST) and alanine transaminase (ALT) levels at week 24. (C) Percentage of patients who showed an increase in lipid levels (total cholesterol $\geq$ $240 \mathrm{mg} / \mathrm{dL}$; low density lipoprotein [LDL] $\geq 160 \mathrm{mg} / \mathrm{dL}$; high density lipoprotein [HDL] $\geq 60 \mathrm{mg} / \mathrm{dL}$; and triglyceride [TG] $\geq 500 \mathrm{mg} / \mathrm{dL}$ ) at week 24 from normal baseline from the main study. TCZ, tocilizumab.
Table 5. Adverse events and adverse drug reactions in the patients who were treated with tocilizumab during the main or extension study period (safety population)

\begin{tabular}{|c|c|c|}
\hline Variable & AEs & ADRs \\
\hline Total no. of events & 470 & 298 \\
\hline Patients with events & $84(94.4)$ & $66(74.2)$ \\
\hline \multicolumn{3}{|l|}{ Intensity of events ${ }^{\mathrm{a}}$} \\
\hline Mild & $401(85 \cdot 3)$ & $251(84.2)$ \\
\hline Moderate & $52(11.1)$ & $34(11.4)$ \\
\hline Severe & $17(3.6)$ & $13(4 \cdot 4)$ \\
\hline Serious events & 29 & 19 \\
\hline Events leading to discontinuation & 21 & 21 \\
\hline $\begin{array}{l}\text { Events leading to dose } \\
\text { interruption }\end{array}$ & 25 & 13 \\
\hline Death & $1^{b}$ & $1^{b}$ \\
\hline \multicolumn{3}{|l|}{ No. of common AEs by SOC } \\
\hline Gastrointestinal disorders & 69 & 28 \\
\hline Respiratory disorders & 67 & 42 \\
\hline Hepatobiliary disorders & 66 & 54 \\
\hline $\begin{array}{l}\text { Metabolic \& nutritional disor- } \\
\text { ders }\end{array}$ & 49 & 42 \\
\hline Skin and appendage disorders & 40 & 21 \\
\hline Musculoskeletal disorders & 37 & 9 \\
\hline White cell \& RES disorders & 37 & 35 \\
\hline $\begin{array}{l}\text { Body as a whole-general } \\
\text { disorders }\end{array}$ & 14 & 10 \\
\hline Nervous system disorders & 19 & 10 \\
\hline Cardiovascular disorders & 9 & 6 \\
\hline Infection-related events & 72 & 55 \\
\hline Patients with infectious events & $47(52.8)$ & $37(41.6)$ \\
\hline $\begin{array}{l}\text { Infectious events/10o patient } \\
\text { years, \% }\end{array}$ & $77 \cdot 5$ & 59.2 \\
\hline Serious infectious events & 10 & 9 \\
\hline $\begin{array}{l}\text { Patients with serious infectious } \\
\text { events }\end{array}$ & $8(9.0)$ & $7(7.9)$ \\
\hline $\begin{array}{l}\text { Serious infectious events/100 } \\
\text { patient years, \% }\end{array}$ & 10.8 & $9 \cdot 7$ \\
\hline Malignancy/Pre-malignancy & $2^{c}$ & $2^{c}$ \\
\hline
\end{tabular}

Values are presented as number or number (\%).

AE, adverse event; ADR, adverse drug reaction; SOC, system organ class; RES, reticulo-endothelial system.

${ }^{a}$ Number of events (column \% for each category).

${ }^{\mathrm{b}}$ One patient died from sepsis due to urinary tract infection.

${ }^{\mathrm{c}}$ Lung adenocarcinoma and uterine cervix dysplasia occurred. 
period. Neutropenia at any time point was observed in 34 patients $(38.2 \%)$, the majority of whom $(n=27)$ were of grade 1 or 2 . The elevated level of AST above normal was observed during the study in 34 patients (38.2\%). These elevations were $<3$-fold the upper limit of normal, except for one patient. The level of serum ALT was elevated above normal upper limit in $45.4 \%(n=39)$ of the patients with the initial normal level. Most had serum ALT level $<3$-fold the upper limit of normal. The number of patients who had initially normal, but elevated levels of cholesterol ( $\geq 240 \mathrm{mg} / \mathrm{dL}), \mathrm{LDL}(\geq 160 \mathrm{mg} / \mathrm{dL}), \mathrm{HDL}(\geq$ $60 \mathrm{mg} / \mathrm{dL})$, and $\mathrm{TG}(\geq 500 \mathrm{mg} / \mathrm{dL})$ at week 72 was $6(7.1 \%)$, $5(5.6 \%), 22(43.1 \%)$, and o (०\%), respectively. Lipid ratios including total cholesterol/HDL, LDL/HDL, and nonHDL/HDL increased at week 72. Increases of total cholesterol/HDL, LDL/HDL, and non-HDL/HDL by more than $30 \%$ were found in $12.4 \%(n=11), 21.3 \%(n=19)$, and $22.5 \%(n=20)$ patients, respectively.

\section{Parameters associated with DAS28 remission at week 72}

We looked for demographic or clinical parameters associated with DAS28 remission at week 72 by comparing the patients with remission and those without remission. Univariate analysis showed that the bigger change of DAS28 from the baseline at week 12, EULAR good response, and lower initial TJC were associated with DAS28 remission at week 72 (Table 6).

\section{DISCUSSION}

The results of the main 24-week trial demonstrated that add-on infusion of TCZ $8 \mathrm{mg} / \mathrm{kg}$ rapidly lead to clinical improvements in Korean patients with active RA refractory to conventional DMARD therapy including MTX. Significantly more patients with TCZ treatment achieved ACR2O and ACR50 responses, DAS28 remission, and EULAR good response with the improvements of symptoms, signs, and laboratory measurements, such as hemoglobin and acute phase reactants, compared with the control group at week 24. These results were generally comparable to previous reports from Japanese or Caucasians [7,9-11,20]. Most previous studies in which ACR7o achievement rate of TCZ treated patients was significantly superior to that of the placebo group.
However, ACR7o response rate at week 24 was relatively low (4.3\%) and did not differ from the placebo in the present study. The placebo group also showed lower ACR20/50/70 response rates compared with previous studies. ACR70 response rate similar to the results of previous studies was delayed until week 72 in our study. During the following 52 -week extension study, the improvements at 24 weeks were maintained in the majority of the subjects. Clinical efficacy of added TCZ did not differ according to background DMARD therapy during the main and extension studies. A previous study reported no difference in ACR2o response according to the number of DMARDs as a background therapy [7].

The proportion of patients with ACR20/50/70 response, DAS28 remission, and EULAR good response increased continuously when they were maintained on TCZ treatment. Clinical remission, represented by DAS28 remission, was achieved by $67 \%$ of patients treated with TCZ infusion for 72 weeks. This population would benefit most from long-term TCZ treatment. DAS28 remission at week 24 has been associated with a younger age ( $<55$ years) [21]. Another study reported that short disease duration $(<4.8$ years) and lower disease activity (DAS28 < 5.23) were predictors of remission at week 52 [22]. Presently, the change of DAS28 at week 12, EULAR good response, and initial TJC were associated with DAS28 remission at week 72 (Table 6). Thus, EULAR good response at week 12 can be a favorable predictor of DAS28 remission at week 72.

General safety profile in our study was drawn from 89 patients treated with TCZ once or more during the main or extension study period (Table 5). They had a total of $470 \mathrm{AEs}, 29$ serious AEs, and $21 \mathrm{AEs}$ leading to discontinuation during a mean duration of $1.04 \pm 0.31$ years. These figures, roughly estimated, were higher compared with from a prior study in which overall rates of any AEs, serious AEs, and AEs leading to discontinuation in TCZ clinical trials 278.2, 14.4, and 5.8 events per 100 patient-years, respectively [23].

In terms of intensity of AE, our study more extensively collected AEs of mild to moderate intensity, rather than severe $\mathrm{AE}$, as the frequency of severe $\mathrm{AE}$ was little different between our and previous reports.

As expected with the involvement of IL-6 in the immune response against infection [24] and previous reports on TCZ treatment [7,9-11,20,25], infection occurred 
Table 6. Demographic and clinical parameters associated with DAS28 remission at week 72

\begin{tabular}{|c|c|c|c|}
\hline Variable & OR & $95 \% \mathrm{CI}$ & $p$ value \\
\hline \multicolumn{4}{|l|}{ Demographic factors } \\
\hline Age & 1.015 & $0.946-1.089$ & NS \\
\hline Male & 1.579 & $0.145-17.212$ & NS \\
\hline Smoker & 0.476 & $0.027-8.418$ & NS \\
\hline Prior cardiovascular disease & 0.686 & $0.158-2.985$ & NS \\
\hline \multicolumn{4}{|l|}{ Baseline disease factors } \\
\hline Disease duration & 1.846 & $0.382-8.922$ & NS \\
\hline ACR functional class & 0.637 & $0.226-1.799$ & NS \\
\hline Rheumatoid factor positivity & 0.999 & $0.995^{-1.003}$ & NS \\
\hline $\mathrm{DAS} 28$ & 0.742 & $0.225-2.446$ & NS \\
\hline TJC & 0.901 & $0.820-0.990$ & 0.0301 \\
\hline SJC & 0.815 & $0.624-1.064$ & NS \\
\hline Patient's pain VAS ${ }^{a}$ & 0.988 & $0.952-1.024$ & NS \\
\hline Patient's global VAS ${ }^{\mathrm{b}}$ & 0.970 & $0.934-1.007$ & NS \\
\hline Physician's global VAS ${ }^{\mathrm{c}}$ & 0.978 & $0.933-1.026$ & NS \\
\hline ESR & 1.002 & $0.973-1.032$ & NS \\
\hline CRP & 0.804 & $0.570-1.134$ & NS \\
\hline \multicolumn{4}{|l|}{ Background therapy } \\
\hline No. of DMARDs & 0.686 & $0.158-2.985$ & NS \\
\hline MTX dose & 0.935 & $0.744-1.176$ & NS \\
\hline Concurrent oral steroids & 1.407 & $0.199-9.963$ & NS \\
\hline \multicolumn{4}{|l|}{ Early response of tocilizumab therapy } \\
\hline Change in DAS28 from baseline at week 12 & 6.084 & $1.612-22.965$ & 0.0077 \\
\hline EULAR good response at week 12 & 23.997 & $2.482-232.027$ & 0.0060 \\
\hline
\end{tabular}

DAS28, disease activity score in 28 joints; OR, odds ratio; CI, confidence interval; NS, not significant; ACR, American College of Rheumatology; TJC, tender joint count; SJC, swollen joint count; VAS, visual analog scale; ESR, erythrocyte sedimentation rate; CRP, C-reactive protein; DMARD, disease modifying anti-rheumatic drug; MTX, methotrexate; EULAR, European League Against Rheumatism.

${ }^{\text {a}}$ Patient's pain VAS, patient's assessment of pain by VAS (o-100 scale).

${ }^{\text {b}}$ Patient's global VAS, patient's global assessment of disease activity by VAS (o-100 scale).

'Physician's global VAS, physician's global assessment of disease activity by VAS (o-10o scale).

more frequently in those receiving TCZ than controls during the study. Upper respiratory tract infection was the most common, and serious infection also occurred more often in the TCZ group. TCZ can mask signs of infection, such as fever and general malaise [26]. Thus, infection should be always monitored in patients treated with TCZ. Interferon $\gamma($ IFN- $\gamma$ ) plays a role in the immune response to tuberculosis. IL-6 production induced in response to infection by Mycobacterium tuberculosis inhibits the responsiveness of macrophages towards IFN- $\gamma[27]$. In addition, in vitro IFN- $\gamma$ production in response to mycobacterial antigen exposure is not impaired by TCZ [28]. These observations suggest a low risk for tuberculosis reactivation during TCZ therapy. In this trial, pre-screening test for latent tuberculosis was performed; patients with latent tuberculosis were enrolled after appropriate treatment with anti- tuberculosis medication. There was no specific infection related with tuberculosis during the study period.

Two cases of malignancy or pre-malignant lesion occurred in the TCZ group. One was a lung adenocarcinoma and the other was uterine cervical dysplasia. IL-6 
appears to be a potentially causative factor of malignant diseases [29]. The carcinogenesis risk of IL-6 cannot be excluded until further epidemiologic surveillance data are available.

The reduction in neutrophil count in patients receiving TCZ is consistent with that reported previously [9-11]. Neutropenia was usually mild and transient, and was not associated with infection or fever. Some possible mechanisms of lowered neutrophil count by TCZ include blocking IL-6-induced neutrophil survival, down-regulation of other inflammatory cytokines, and the migration of neutrophils from the circulation into tissues [30,31].

Most common AEs involved in liver and biliary system were hepatic enzyme elevations without any clinical symptoms in our study, consistent with previous reports [9-11]. These increases were generally mild and transient, with normalization occurred spontaneously or after temporary interruption of TCZ infusion.

Cardiovascular diseases are a major cause of mortality in patients with RA [32] and risk factors including lipid profile and their modification are a serious concern [33]. Although cardiovascular complications were rarely found in our study compared with previous studies $[8,10]$, plasma lipid levels rose in the TCZ group. These increases might be associated with the control of disease activity. Patients with active RA often have lower lipid concentrations than the general population in association with the inflammatory process, and increases have been seen with improvement in chronic inflammation [34]. However, atherogenic indices, such as the LDL/ HDL and non-HDL/HDL ratios, were elevated by $>30 \%$ from baseline values in about $20 \%$ of patients. Thus, long-term detrimental effect to cardiovascular system cannot be excluded in those receiving TCZ. The Japanese guideline recommends monitoring serum lipid level during TCZ treatment [35].

Decline in RF titer has been observed in patients with RA treated with TNF blocking agents $[36,37]$ and it has been reportedly associated with treatment response [38]. However, there have been few reports on the alteration of serum RF level by the treatment with TCZ. From our study, serum RF titer was markedly decreased in the TCZ group compared to the placebo group at 24 weeks. This phenomenon was described in an earlier study on TCZ [11]. However, there was a contradictory report of no significant RF level change and no correlation between clinical response and RF levels [39]. The mechanism of the reduction in RF titer in response to biological treatment is not fully understood. IL-6 blockade might inhibit B cell autoantibody production as in TNF-blocking [40]. Interestingly, our extension study showed that serum RF titer at week 72 did not differ from the baseline. The initial decline of RF production by TCZ was not sustainable, but independent of long-term clinical response. There are no conclusive evidences so far on the reduction of RF level and/or its association with clinical improvement during TCZ therapy. It requires further investigation.

The current study does have limitations. The longterm effect of TCZ on structural damage and quality of life in patients with RA was not evaluated and it requires further studies. The efficacy of TCZ monotherapy was reported to be comparable to the combination of TCZ and DMARDs [41], but it remains to be confirmed in Korean patients in the future study. Many biologic agents including TNF blocking agents have been already used for patients with active RA refractory to conventional DMARD therapy in Korea. Comparative studies among biologic agents including TCZ will ascertain which one is better for the specified patients with active RA. Future studies should include the assessment of longer-term AEs which can occur 72 weeks after TCZ administration. It is also required to investigate how long TCZ efficacy is maintained and how to taper TCZ after the remission.

\section{KEY MESSAGE}

1. Tocilizumab (TCZ) infusion ( $8 \mathrm{mg} / \mathrm{kg}$ ) add-on is highly efficacious in Korean patients with active rheumatoid arthritis (RA) refractory to conventional disease modifying anti-rheumatic drugs (DMARDs) including methotrexate (MTX).

2. DAS28 (disease activity score in 28 joints) remission was achieved in one-thirds of the patients at week 72 and associated with European League Against Rheumatism (EULAR) good response at week 12. Week 12 EULAR good response could be a predictor of the remission with long-term TCZ therapy.

3. TCZ with DMARDs including MTX is well-tolerated in the majority of patients during the 72 
week treatment period, although TCZ therapy has possible adverse events including serious infection, abnormal liver function, atherogenic lipid profile, and malignancy.

\section{Conflict of interest}

This work was supported by JW Pharmaceutical Co. Ltd.

\section{REFERENCES}

1. Choy EH, Panayi GS. Cytokine pathways and joint inflammation in rheumatoid arthritis. N Engl J Med 2001;344:907-916.

2. Smolen JS, Aletaha D, Koeller M, Weisman MH, Emery P. New therapies for treatment of rheumatoid arthritis. Lancet 2007;370:1861-1874.

3. Desroches M, Louis G, Gleizes A, Krzysiek R, Emilie D. Treatment failure with antagonists of TNF- $\alpha$ : mechanisms and implications for the care of patients. Eur Cytokine Netw 2010;21:226-231.

4. Kishimoto T. Interleukin-6: discovery of a pleiotropic cytokine. Arthritis Res Ther 2006;8 Suppl 2:S2.

5. Madhok R, Crilly A, Watson J, Capell HA. Serum interleukin 6 levels in rheumatoid arthritis: correlations with clinical and laboratory indices of disease activity. Ann Rheum Dis 1993;52:232-234.

6. Mihara M, Kasutani K, Okazaki M, et al. Tocilizumab inhibits signal transduction mediated by both mIL-6R and sIL-6R, but not by the receptors of other members of IL-6 cytokine family. Int Immunopharmacol 2005;5:17311740.

7. Genovese MC, McKay JD, Nasonov EL, et al. Interleukin-6 receptor inhibition with tocilizumab reduces disease activity in rheumatoid arthritis with inadequate response to disease-modifying antirheumatic drugs: the tocilizumab in combination with traditional disease-modifying antirheumatic drug therapy study. Arthritis Rheum 2008;58:2968-2980.

8. Nishimoto N, Miyasaka N, Yamamoto K, Kawai S, Takeuchi T, Azuma J. Long-term safety and efficacy of tocilizumab, an anti-IL-6 receptor monoclonal antibody, in monotherapy, in patients with rheumatoid arthritis (the STREAM study): evidence of safety and efficacy in a 5-year extension study. Ann Rheum Dis 2009;68:1580-1584.
9. Maini RN, Taylor PC, Szechinski J, et al. Double-blind randomized controlled clinical trial of the interleukin-6 receptor antagonist, tocilizumab, in European patients with rheumatoid arthritis who had an incomplete response to methotrexate. Arthritis Rheum 2006;54:28172829 .

10. Emery P, Keystone E, Tony HP, et al. IL-6 receptor inhibition with tocilizumab improves treatment outcomes in patients with rheumatoid arthritis refractory to anti-tumour necrosis factor biologicals: results from a 24-week multicenter randomised placebo-controlled trial. Ann Rheum Dis 2008;67:1516-1523.

11. Smolen JS, Beaulieu A, Rubbert-Roth A, et al. Effect of interleukin-6 receptor inhibition with tocilizumab in patients with rheumatoid arthritis (OPTION study): a double-blind, placebo-controlled, randomised trial. Lancet 2008;371:987-997.

12. Smolen JS, Landewe R, Breedveld FC, et al. EULAR recommendations for the management of rheumatoid arthritis with synthetic and biological disease-modifying antirheumatic drugs: 2013 update. Ann Rheum Dis 2014;73:492-509.

13. Arnett FC, Edworthy SM, Bloch DA, et al. The American Rheumatism Association 1987 revised criteria for the classification of rheumatoid arthritis. Arthritis Rheum 1988;31:315-324.

14. Joint Committee for the Development of Korean Guidelines for Tuberculosis, Korea Centers for Disease Control and Prevention. Korean Guidelines for Tuberculosis. Seoul: Korea Centers for Disease Control and Prevention, 2011.

15. Paulus HE, Egger MJ, Ward JR, Williams HJ. Analysis of improvement in individual rheumatoid arthritis patients treated with disease-modifying antirheumatic drugs, based on the findings in patients treated with placebo. The Cooperative Systematic Studies of Rheumatic Diseases Group. Arthritis Rheum 1990;33:477-484.

16. Prevoo ML, van 't Hof MA, Kuper $\mathrm{HH}$, van Leeuwen MA, van de Putte LB, van Riel PL. Modified disease activity scores that include twenty-eight-joint counts. Development and validation in a prospective longitudinal study of patients with rheumatoid arthritis. Arthritis Rheum 1995;38:44-48.

17. van Gestel AM, Prevoo ML, van 't Hof MA, van Rijswijk $\mathrm{MH}$, van de Putte LB, van Riel PL. Development and validation of the European League Against Rheumatism 
response criteria for rheumatoid arthritis. Comparison with the preliminary American College of Rheumatology and the World Health Organization/International League Against Rheumatism Criteria. Arthritis Rheum 1996;39:3440.

18. Fries JF, Spitz P, Kraines RG, Holman HR. Measurement of patient outcome in arthritis. Arthritis Rheum 1980;23:137-145.

19. Uppsala Monitoring Centre. The WHO adverse reaction terminology: WHO-ART [Internet]. Uppsala (SE): Uppsala Monitoring Centre, 2017 [cited 2017 Nov 7]. Available from: http://www.umc-products.com/graphics/28010.pdf.

20. Yazici Y, Curtis JR, Ince A, et al. Efficacy of tocilizumab in patients with moderate to severe active rheumatoid arthritis and a previous inadequate response to disease-modifying antirheumatic drugs: the ROSE study. Ann Rheum Dis 2012;71:198-205.

21. Pers YM, Fortunet C, Constant E, et al. Predictors of response and remission in a large cohort of rheumatoid arthritis patients treated with tocilizumab in clinical practice. Rheumatology (Oxford) 2014;53:76-84.

22. Kojima T, Kaneko A, Hirano Y, et al. Early aggressive intervention with tocilizumab for rheumatoid arthritis increases remission rate defined using a Boolean approach in clinical practice. Mod Rheumatol 2012;22:370-375.

23. Schiff MH, Kremer JM, Jahreis A, Vernon E, Isaacs JD, van Vollenhoven RF. Integrated safety in tocilizumab clinical trials. Arthritis Res Ther 2011;13:R141.

24. Van der Meide PH, Schellekens H. Cytokines and the immune response. Biotherapy 1996;8:243-249.

25. Campbell L, Chen C, Bhagat SS, Parker RA, Ostor AJ. Risk of adverse events including serious infections in rheumatoid arthritis patients treated with tocilizumab: a systematic literature review and meta-analysis of randomized controlled trials. Rheumatology (Oxford) 2011;50:552-562.

26. Fujiwara H, Nishimoto N, Hamano Y, et al. Masked early symptoms of pneumonia in patients with rheumatoid arthritis during tocilizumab treatment: a report of two cases. Mod Rheumatol 2009;19:64-68.

27. Nagabhushanam V, Solache A, Ting LM, Escaron CJ, Zhang JY, Ernst JD. Innate inhibition of adaptive immunity: Mycobacterium tuberculosis-induced IL-6 inhibits macrophage responses to IFN-gamma. J Immunol 2003;171:4750-4757.

28. Ogata A, Mori M, Hashimoto S, et al. Minimal influence of tocilizumab on IFN-gamma synthesis by tuberculosis antigens. Mod Rheumatol 2010;20:130-133.

29. Akira S, Taga T, Kishimoto T. Interleukin-6 in biology and medicine. Adv Immunol 1993:54:1-78.

30. Asensi V, Valle E, Meana A, et al. In vivo interleukin-6 protects neutrophils from apoptosis in osteomyelitis. Infect Immun 2004;72:3823-3828.

31. Suwa T, Hogg JC, Quinlan KB, Van Eeden SF. The effect of interleukin-6 on L-selectin levels on polymorphonuclear leukocytes. Am J Physiol Heart Circ Physiol 2002;283:H879-H884.

32. Meune C, Touze E, Trinquart L, Allanore Y. Trends in cardiovascular mortality in patients with rheumatoid arthritis over 50 years: a systematic review and meta-analysis of cohort studies. Rheumatology (Oxford) 2009;48:1309-1313.

33. Martin-Martinez MA, Gonzalez-Juanatey C, Castaneda S, et al. Recommendations for the management of cardiovascular risk in patients with rheumatoid arthritis: scientific evidence and expert opinion. Semin Arthritis Rheum 2014;44:1-8.

34. Robertson J, Peters MJ, McInnes IB, Sattar N. Changes in lipid levels with inflammation and therapy in RA: a maturing paradigm. Nat Rev Rheumatol 2013;9:513-523.

35. Koike R, Harigai M, Atsumi T, et al. Japan College of Rheumatology 2009 guidelines for the use of tocilizumab, a humanized anti-interleukin- 6 receptor monoclonal antibody, in rheumatoid arthritis. Mod Rheumatol 2009;19:351-357.

36. De Rycke L, Verhelst X, Kruithof E, et al. Rheumatoid factor, but not anti-cyclic citrullinated peptide antibodies, is modulated by infliximab treatment in rheumatoid arthritis. Ann Rheum Dis 2005;64:299-302.

37. Bos WH, Bartelds GM, Wolbink GJ, et al. Differential response of the rheumatoid factor and anticitrullinated protein antibodies during adalimumab treatment in patients with rheumatoid arthritis. J Rheumatol 2008;35:1972-1977.

38. Mikuls TR, O'Dell JR, Stoner JA, et al. Association of rheumatoid arthritis treatment response and disease duration with declines in serum levels of IgM rheumatoid factor and anti-cyclic citrullinated peptide antibody. Arthritis Rheum 2004;50:3776-3782.

39. Epis O, Alpini C, Marceglia S, Casu C, Giacomelli L, Bruschi E. Clinical and serological response to tocilizumab in patients with rheumatoid arthritis. J Med Diagn Methods 2013;2:127.

40. Anolik JH, Ravikumar R, Barnard J, et al. Cutting edge: 
anti-tumor necrosis factor therapy in rheumatoid arthritis inhibits memory B lymphocytes via effects on lymphoid germinal centers and follicular dendritic cell networks. J Immunol 2008;180:688-692.

41. Dougados M, Kissel K, Sheeran T, et al. Adding tocilizum- $\mathrm{ab}$ or switching to tocilizumab monotherapy in methotrexate inadequate responders: 24 -week symptomatic and structural results of a 2-year randomised controlled strategy trial in rheumatoid arthritis (ACT-RAY). Ann Rheum Dis 2013;72:43-50. 